\title{
Interpretación constitucional Constitutional Interpretation
}

\author{
Abraham Sánchez Sánchez \\ Universidad de Rosario - Bogotá \\ abraham sanch@yahoo.es \\ Recibido / received: 18/08/2017 \\ Aceptado / accepted: 04/09/2017 \\ DOI: https://doi.org/10.20318/eunomia.2017.3815
}

\begin{abstract}
Resumen
Mediante este trabajo se efectúa una presentación general de la interpretación constitucional, con fundamento en los principales temas de discusión a que ha dado lugar su reciente aparición en el panorama jurídico. Que la Constitución sea objeto de interpretación depende de la incorporación de sus cláusulas en un documento escrito dotado de carácter normativo. A partir de estas condiciones se hace hincapié en el contenido material de las constituciones actuales, así como en la indeterminación de sus preceptos y en el papel de los métodos tradicionales para la interpretación constitucional, entendida, por amplios sectores, como especial y necesitada de métodos propios. Asimismo, se aborda lo referente a los intérpretes de la Constitución, centrando la atención en el legislador y en el Tribunal o Corte Constitucional que, en cuanto máximo intérprete, entra en contacto con los jueces ordinarios y con el propio legislador, relación esta última que se muestra particularmente problemática, al grado de evidenciar una tensión entre Constitución y democracia. Además se advierte acerca de situaciones riesgosas en las que se puede incurrir so pretexto de la interpretación de la Constitución, con afectación de su carácter escrito y de su condición normativa, que son, precisamente, las condiciones que hacen posible la interpretación constitucional.
\end{abstract}

\section{Palabras clave}

Interpretación, Constitución, métodos de interpretación, tribunales constitucionales.

\begin{abstract}
This article presents a general view of constitutional interpretation based on the main topics that are being discussed currently. First, to be an object of interpretation, the Constitution needs a written document endowed with normative character. Hereafter we conduct a review of the material content of the current Constitutions, the indetermination of its articles and the role of conventional methods of constitutional interpretation. In addition, it deals with the agents of constitutional interpretation, paying attention to the legislature and the Constitutional Courts. The latter, due to its position of supreme interpreters of the Constitution, has direct and constant contact with the ordinary judiciary and the legislature. This Constitutional Court-legislature relation is particularly problematic because it contains a tension between two concepts: Constitution and Democracy. Finally, the paper remarks the risks associated with constitutional interpretation which affects its written and normative character, the two main requirements that make constitutional interpretation possible.
\end{abstract}

\footnotetext{
* Magistrado Auxiliar de la Corte Constitucional de Colombia.
} 
Keywords
Interpretation, Constitution, methods of interpretation, Constitutional Courts.

SUMARIO. 1. Interpretación y Constitución. 2. La Constitución como norma. 3. La interpretación constitucional como problema y los métodos de interpretación. 4. Los intérpretes de la Constitución. 5. El máximo intérprete constitucional y sus relaciones con los jueces ordinarios y con el legislador. 6. La interpretación constitucional y sus riesgos.

\section{Interpretación y Constitución}

De acuerdo con un entendimiento elemental, la interpretación consiste en dotar de significado y puede aludir al proceso desarrollado con tal propósito o a su resultado último. Cuando el objeto interpretado es la Constitución, los interrogantes iniciales pretenden indagar acerca de las condiciones que hacen posible la búsqueda del sentido de las cláusulas superiores del ordenamiento jurídico, y una de las primeras respuestas destaca como presupuesto indispensable el carácter escrito, que implica la existencia de un documento en el cual se recogen las disposiciones fundamentales del Estado, preceptos cuya expresión textual se sirve de un lenguaje natural.

Aunque el concepto formal, ligado a la expedición de un texto, contribuye a acotar el ámbito de lo interpretable, en cuanto deja por fuera de esa esfera las constituciones consuetudinarias, desde el punto de vista de la evolución histórica la constancia escrita no es supuesto suficiente de la interpretación que recae sobre el documento constitucional. Durante un largo periodo se impuso la índole política de las constituciones escritas, que limitaba su alcance a la regulación de las relaciones entre los tres poderes integrantes de la clásica tridivisión, al paso que el principio de la soberanía parlamentaria desplegó toda su influencia y elevó al legislador, tenido por racional, a una posición prevalente que trasmitía a la ley, dotada de la consecuente primacía entre las fuentes formales del Derecho.

Para que la Constitución deviniera en objeto de interpretación se requería que a su carácter escrito se sumara la connotación jurídica, es decir, que fuera parte del Derecho. Así aconteció tras un proceso de desenvolvimiento que para algunos tiene su punto de inicio en la Constitución de los Estados Unidos, adoptada en 1787 e impulsora de un desarrollo diferente del cumplido en la Europa continental, hasta que el movimiento europeo vino a confluir con el norteamericano, como resultado de una progresivo acercamiento consolidado en la segunda posguerra mundial, de cuyas recíprocas influencias habría surgido la aceptación creciente de la condición normativa de la Constitución.

La juridificación de las constituciones supuso la subordinación tanto del legislador como de la ley a un Derecho superior. El grado de ese sometimiento depende de múltiples factores, entre ellos, de la cobertura de los contenidos constitucionales, que hoy se ha extendido a una multiplicidad de materias que práctica y ampliamente desbordan las teorías que, como la kelseniana, abogaron por constituciones solo dedicadas a procedimientos, en especial a los destinados a la creación normativa, y depuradas al máximo de contenidos sustantivos. 


\section{La Constitución como norma}

A causa de la profusa incorporación de materias, junto a los comunes aspectos organizativos, las constituciones actuales suelen ser la sede de un abigarrado conjunto de preceptos clasificables en variadas categorías, de las que basta mencionar los valores y los principios para percatarse de la complejidad de su conceptualización y tratamiento, que dista bastante de la mayor facilidad que supone el entendimiento y aplicación de las reglas, estructuradas de tal modo que a un supuesto de hecho concreto le sigue una consecuencia ya determinada en la misma disposición.

La confluencia de preceptos de tan diferente estructura ha llevado a sostener que la Constitución, más que una norma, es un conjunto normativo, condición esta que, sin embargo, no despeja todas las dudas suscitadas alrededor de la juridicidad del escalón superior del ordenamiento jurídico interno. De una parte, se piensa que la normatividad de la Constitución no difiere de la que corresponde a la ley, mientras que, de otro lado, se proclama la diferencia, aun cuando se discute si la predicada distinción es cuantitativa o de orden cualitativo.

Si la calidad es el factor que marca la diferencia, la Constitución, en cuanto entidad normativa, sería por completo diferente de las restantes normas del ordenamiento y, particularmente, de la ley. Por el contrario, si prevalece una aproximación cuantitativa, no habría diferencia sustancial entre las normas plasmadas en fuentes subordinadas y las que tienen su asiento en la Constitución, salvo que en el documento superior hallaría sitio un acrecentado número de preceptos que no darían lugar a la típica solución que liga una consecuencia jurídica a la ocurrencia de un supuesto específico.

Concepciones teóricas hay que pretenden hacer de la Constitución el mundo exclusivo de los principios y de la ley el ámbito propio de las reglas, pero tan absoluta separación no es característica de un ordenamiento que cuenta con varios niveles, en cada uno de los cuales bien pueden mezclarse reglas y principios, sin que de esa combinación sea posible exceptuar a las constituciones. En el texto de estas últimas se encuentran reglas y, de la misma manera, aunque los contenidos de la ley se consideren más propicios a las reglas, estas no están exentas de la figuración de los principios.

La indeterminación de las cláusulas no es, entonces, fenómeno que corresponda únicamente a la Constitución, aunque desde un punto de vista cuantitativo cabría sostener no solo que es elevada la cantidad de disposiciones indeterminadas presentes en el documento superior, sino también que su densidad regulativa es todavía más escasa, quizá por cuenta de la composición plural de las instancias políticas que adoptan las constituciones y, desde luego, de la ingente cuantía de grupos, ideologías e intereses existentes en las heterogéneas sociedades contemporáneas, cuya difícil articulación solamente podría lograrse a partir de la inclusión en el texto superior de muy amplias fórmulas de compromiso, propicias a una futura conciliación no prefigurada en la carta constitucional y, por lo mismo, pendiente de la apreciación de variables sometidas a cambios a lo largo del tiempo.

3. La interpretación constitucional como problema y los métodos de interpretación

La interpretación constitucional surge así como un problema nuevo cuando ya la cuestión interpretativa había recorrido un importante camino en otras ramas 
jurídicas, principalmente en los dominios del Derecho Civil que, habiendo experimentado la codificación, fue el campo en el cual se decantaron postulados hermenéuticos que luego pasaron a otros sectores de posterior aparición, en los que fueron asumidos sin grandes dificultades y no obstante la peculiaridad de algunos de sus contenidos.

Cuando en el campo del Derecho Constitucional empezaron a suscitarse las cuestiones inherentes a las labores interpretativas, a fin de responder a las inquietudes que plantean las constituciones como objeto de interpretación jurídica, el empleo de los métodos previamente canonizados por Savigny fue propuesto como solución adecuada. Sin embargo, otras corrientes advirtieron al mismo tiempo que, para enfrentar los problemas generados por la interpretación constitucional, los elementos gramatical, histórico y lógico-sistemático no resultaban apropiados. Respecto de ellos, las posiciones adoptadas varían desde la descalificación fincada en su total inutilidad, hasta una aceptación matizada por su reconocida insuficiencia siempre que de interpretar la Constitución se trate.

La solución basada en el uso de las tradicionales reglas de interpretación tiene sustento en la total equiparación entre Constitución y ley, defendida por Forstoff en aras de la seguridad jurídica y de la inhibición de las facultades del intérprete, pero, en la medida en que la mencionada equiparación no puede sostenerse, la consecuencia referente a la solución de los problemas de la interpretación constitucional mediante la sola aplicación de los criterios tradicionales tampoco es aceptable.

Aun así, resulta exagerado desechar del todo los métodos tradicionales, ya que, trátese de la Constitución o de la ley, la interpretación que se pretenda siempre comporta la búsqueda del significado de una disposición jurídica mediante el empleo de los instrumentos que con tal fin se hayan perfilado, aunque ante los requerimientos de un nuevo objeto los métodos habituales ya no sean tan decisivos, tengan que ser complementados o deban compartir su espacio con técnicas distintas y prevalentes.

Cualquiera sea su incidencia o el apoyo, mayor o menor, que presten en la interpretación constitucional, los criterios clásicos llegan a este debate con las transformaciones experimentadas en su propio devenir. Estos cambios influyen en su apreciación, así como en el papel que están llamados a cumplir y dependen de aquello que en un momento dado se tenga por significado de un precepto jurídico.

En efecto, si se considera que el significado de una disposición viene dado por su autor o es portado por el mismo texto, aun con independencia de su creador, la actividad interpretativa será un acto cognoscitivo y se orientará al descubrimiento de ese significado previo y único; mas si se estima que el significado no es prefigurado por el autor ni viene inexorablemente incorporado al precepto como posibilidad única, la interpretación no consiste en descubrir, sino en atribuir un significado que, incluso, puede ser escogido entre varias alternativas disponibles.

El entendimiento de la interpretación como atribución de significado es la tendencia dominante ya desde épocas en las que imperaban los métodos clásicos, luego la participación que les corresponda a estos criterios tradicionales cuando se trate de interpretar la Constitución está impregnada de la referida comprensión de la actividad interpretativa y del significado que se busca mediante su despliegue. Esto significa que el propósito de la interpretación constitucional no sea descubrir una voluntad ínsita en los preceptos superiores o absolutamente determinada por cuerpos constituyentes de composición plural, sino atribuir sentido, dirección en la 
cual también deben actuar las técnicas o los métodos propios de la interpretación constitucional.

Los métodos de la interpretación constitucional están llamados a superar la insuficiencia de las herramientas provenientes del Derecho Privado, para hacer efectiva la atribución de significado a las cláusulas del ordenamiento superior. En el cumplimiento de esa tarea, por ejemplo, la actuación aislada del elemento gramatical difícilmente podría dar cuenta del sentido de disposiciones con tan altos niveles de indeterminación y que están destinadas a operar en contextos mudables. Los cambios sociales, a su turno, generan una dinámica que, con gran rapidez, aleja el transcurrir de las constituciones del momento constituyente y de las intenciones de sus autores. De tal manera, los efectos de las constantes transformaciones rebasan la visión estática del elemento histórico y hacen girar su cometido hacia la apreciación de la influencia que tienen las circunstancias causadas por la evolución de la sociedad y de las instituciones en el desarrollo de la interpretación constitucional, Para ello, se le reconoce gran relevancia al método sistemático, que también sale replanteado de su contacto con la Constitución, pues debe atender a la unidad y la coherencia de los intereses involucrados en aquellas situaciones en las que las disposiciones superiores actúan, por lo que no puede quedar reducido a la simple apreciación del lugar que un precepto ocupa en el documento constitucional.

De las reglas enunciadas por Savigny no forma parte el elemento teleológico, cuya importancia en la interpretación constitucional ha sido destacada por algunos sectores que evidencian el vínculo entre la búsqueda de la finalidad de las disposiciones superiores y la realización del orden de valores incorporado en el texto constitucional. Este orden axiológico ha sido concebido como portador de una inmensa potencialidad para incidir en cada ejercicio interpretativo y transformar su orientación y resultados, lo cual le confiere al criterio teleológico una enorme amplitud de miras que, según otros sectores, conduce a confundir su propósito con el de la interpretación misma. Así, la pregunta por el objetivo de un precepto, de inmediato remite a la indagación sobre los métodos para identificar ese sentido o finalidad, sin que, en realidad, haya avance respecto de la cuestión central que plantea toda interpretación.

En palabras de Hesse, en lo que respecta a la interpretación constitucional, las reglas tradicionales apenas ofrecen una explicación parcial de un panorama complejo y comprehensivo de distintos puntos de vista que deben ser relacionados, coordinados y valorados con la ayuda de varios principios. Así, el principio de unidad de la Constitución obliga a involucrar el conjunto pertinente de preceptos constitucionales, que deben ser interpretados evitando las contradicciones y procurando decisiones consonantes con las decisiones básicas de la Carta. Por su parte, el principio de concordancia práctica invita a coordinar los bienes jurídicos involucrados manteniendo su entidad y sin apresurarse a efectuar una ponderación que lleve al sacrificio de uno para realizar otro. Además, el criterio de corrección funcional le impone al intérprete el deber de conservar la distribución de las funciones estatales de acuerdo con lo constitucionalmente asignado a los respectivos agentes y el principio de la eficacia integradora supone la realización de la unidad política pretendida por la Constitución, lo que exige preferir las soluciones que promuevan y mantengan esa unidad.

La relación entre los criterios clásicos y los que han sido postulados como propios de la interpretación constitucional no es asunto pacífico. La posición defendida depende de la manera en que sea asumida la Constitución y el vínculo entre sus diferentes cláusulas. De este modo, quien piense que la Constitución es cualitativamente diferente del resto del ordenamiento y de la ley en particular, 
pondrá el énfasis en los criterios que se estiman propios de la interpretación constitucional. Pero si se sostiene que la comentada distinción, con todo y su importancia, es solo cuantitativa, es posible que se imponga una tendencia que, con mayor o menor intensidad, incline la balanza del lado de las reglas tradicionales, incluso bajo la advertencia de que deben responder a un reto más grande que los usuales o soportar replanteamientos que les doten de mejor aptitud para responder a un problema complejo.

Asimismo, si se acepta que las normas constitucionales, y en especial las de derechos fundamentales, están en una tensión permanente y proclive al conflicto, que puede desatarse o ponerse en evidencia a raíz de un caso concreto, no resulta extraño que se recurra a procedimientos que, como los test, traten de ponderar o de lograr el mejor balance entre los derechos enfrentados. Sin embargo, si la tesis que propone el conflicto real o latente entre distintas cláusulas constitucionales no es aceptada, lo coherente sería descartar la ponderación y sus procedimientos para, basándose en la unidad de la Constitución, sostener que el caso se rige por una de las cláusulas en juego y no por la otra e, incluso, que es factible resolver la cuestión mediante una subsunción. Esto en radical oposición a otras tendencias para las cuales el razonamiento silogístico y la subsunción están definitivamente desterrados del Derecho Constitucional.

\section{Los intérpretes de la Constitución}

La mención de ponderaciones y subsunciones evoca, de inmediato, lo atinente a los intérpretes de la Constitución, tema ligado a otro concerniente a la necesidad de saber a quiénes está dirigido el documento constitucional. De nuevo las respuestas dependen de la idea de Constitución que se prohíje. Así, al asumir teóricamente que el texto superior, aun dotado de carácter normativo, únicamente contiene los procedimientos para la creación de los preceptos que en la escala jerárquica están situados por debajo de la Constitución, la inevitable conclusión es que ésta se dirige de preferencia al legislador que, a su vez, sería su intérprete privilegiado.

Las constituciones que además de los aspectos organizativos y procedimentales abrigan numerosos contenidos de orden material también están dirigidas al legislador, encargado de desarrollarlas mediante la ley y ese desarrollo supone que el órgano legislativo interpreta la Constitución. No obstante, habría que añadir que aun cuando se trata del primer intérprete no es el único, pues en virtud de su condición normativa, los contenidos del documento constitucional se dirigen a todos los órganos del Estado. Al irradiar el ordenamiento jurídico entran en contacto con numerosos agentes y operadores que, teniéndolos a su alcance, pueden verse precisados a interpretarlos, ejercicio del que tampoco se excluye a los particulares, en cuanto sujetos de los derechos y deberes plasmados en la Constitución.

Puestas de este modo las cosas, el problema se desplaza hacia la indispensable articulación de las interpretaciones, para impedir que la Constitución se disuelva en una multiplicidad de lecturas equivalente a la cantidad de intérpretes que puedan surgir a propósito de los más variados asuntos, todo lo cual hace pensar en la necesaria previsión de mecanismos de unificación con la aptitud jurídica suficiente para imponer con fuerza vinculante los significados que deben guiar la actividad interpretativa.

Aparece, entonces, la previsible figura de un intérprete supremo de la Constitución, que en los regímenes actuales suele ser un tribunal o corte constitucional, investida por el propio texto superior de competencias de control dirigidas a hacer valer la supremacía de la Carta, merced al cumplimiento de una 
función de índole judicial -o jurisdiccional si el referido órgano es situado fuera del poder judicial- llevada a cabo con fundamento en métodos y criterios jurídicos.

5. El máximo intérprete constitucional y sus relaciones con los jueces ordinarios y con el legislador

La función encomendada al órgano erigido como máximo juez constitucional lleva a indagar acerca de sus relaciones con los jueces ordinarios y con el legislador, primer intérprete de la Constitución. En cuanto hace a los jueces ya ha sido superada la separación absoluta entre la jurisdicción constitucional, a cuya cabeza se encuentra el supremo intérprete de la Carta, y la jurisdicción ordinaria, disociación que se cimentaba en la pretensión de dejar a los jueces comunes la interpretación y aplicación de la ley, y encargar al tribunal constitucional, en régimen de excluyente monopolio, la interpretación y aplicación del documento constitucional.

El carácter normativo de la Constitución y la materialidad de buena parte de sus contenidos han sido factores propicios a la interactuación de las jurisdicciones constitucional y ordinaria, colaboración que se manifiesta en el papel que le corresponde a la Constitución en las tareas encomendadas a los jueces ordinarios, quienes la tienen a su alcance y deben hacer interpretación constitucional de la ley que les permite resolver un caso concreto. También en la actuación de los tribunales y cortes constitucionales que, aun cuando encargados de la interpretación definitiva de la Constitución, deben acometer la interpretación de la ley para hacer posible el control de constitucionalidad de la obra del legislador.

En cualquiera de los dos escenarios es posible advertir que la interrelación entre la jurisdicción constitucional y la ordinaria implica la confluencia de la interpretación de la Constitución y de la ley, a propósito de las facultades otorgadas a cada jurisdicción, debiéndose anotar que en el caso de la jurisdicción constitucional se presenta otra relación, ya no del máximo intérprete de la Constitución con los jueces, sino con el legislador, intérprete primario del texto superior y perteneciente a una rama del poder público distinta de la judicial.

Según lo anotado, el legislativo interpreta la Constitución a fin de desarrollarla mediante la ley, que se presenta ante el tribunal que ha de juzgar su constitucionalidad investida de la legitimidad democrática que le da el hecho de haber sido adoptada por el que es órgano representativo por excelencia, a causa de su elección popular directa y de albergar en su seno la más completa representación de diversos sectores e intereses, incluidas las corrientes minoritarias. Estos aspectos marcan un contraste radical con los jueces de una corte constitucional, pocos y carentes de la unción discernida por el pueblo, pese a lo cual, en su condición de máximos intérpretes de la Constitución, tienen la última palabra sobre la ley de innegable origen democrático y a la que pueden separar del ordenamiento.

Los poderes del supremo juez de la constitucionalidad ejercidos aun en contra de la decisión del legislador han dado lugar a la denominada objeción contramayoritaria, que cuestiona el control de constitucionalidad en cuanto mecanismo capaz de dar al traste con las leyes, imponiéndose así a la interpretación constitucional hecha por el legislador. Las posiciones favorables a la existencia del control de constitucionalidad han ensayado un amplio repertorio de soluciones, entre las que es común mencionar la observancia del self restrain por tribunales y cortes constitucionales, la especial consideración de la dignidad democrática de la ley, la nulidad como recurso último y extremo ante violaciones flagrantes de normas constitucionales o el agotamiento de las posibilidades que harían viable una interpretación de la ley conforme a la Constitución. 
Desde otras orillas, la franca prevención hacia la supremacía de los jueces en la interpretación constitucional se expresa mediante la recomendación de idear o fortalecer mecanismos destinados a hacer valer la participación popular en la interpretación de la Constitución. Sea que se persiga reemplazar el control judicial de constitucionalidad o morigerar la influencia de un tribunal erigido en supremo intérprete constitucional, resulta indispensable destacar la propuesta consistente en involucrar en las toma de las decisiones últimas acerca de los significados del documento superior a intérpretes distintos del legislador o del tribunal constitucional, lo que se acompasa con el carácter normativo de la Constitución y con el surgimiento de nuevos agentes de su interpretación. Esto sin olvidar que algunos de los sistemas de jurisdicción constitucional existentes brindan oportunidades de intervención en los procesos de constitucionalidad a ciudadanos, grupos, centros universitarios, instituciones privadas y públicas interesadas en los resultados 0 encargadas de funciones de representación social.

De todas maneras, las instancias llamadas a controlar la interpretación constitucional que el legislador vierte en una ley, o a expresar su parecer en relación con el problema que se haya suscitado, deberán tener en cuenta que de la Constitución no se deriva una sola opción de desarrollo y que, por ello, el legislador está asistido por una amplia libertad de configuración que le permite escoger entre varias alternativas plausibles la que se adopte bajo la forma de ley por haber obtenido el respaldo de una mayoría, que en el futuro puede cambiar e incluso preferir una iniciativa diferente, siempre dentro de los márgenes de la Constitución que así, en lugar de aportar respuestas únicas, instaura límites que los órganos de control constitucional deben cuidar, para que no sean traspasados por interpretaciones contrarias a las que, válidamente, cabría derivar de los contenidos superiores del ordenamiento jurídico.

En cualquier caso, en la tensión entre la interpretación que el legislador provee y la que con fuerza vinculante adopta el máximo juez constitucional se manifiesta una tensión de fondo que, al contraponer la Constitución a la democracia, incide en la importancia que se le asigne a la interpretación del documento superior, pues cuando se le reconoce prevalencia a la opción democrática se tiende a procurar lecturas minimalistas de la Constitución, cuyo contenido puede quedar pendiente de la activación de los mecanismos que permitan conocer la voluntad popular, en tanto que si la preferencia se ubica del lado de la Constitución, es más probable que se promueva una interpretación maximalista de sus contenidos.

\section{La interpretación constitucional y sus riesgos}

Sea de lo anterior lo que fuere, parece inevitable que los riesgos acompañen la interpretación constitucional, ya porque al texto interpretado se le vacíe de contenido o se le someta a constantes cambios aun de tinte plebiscitario, ora porque se traspasen sus posibilidades interpretativas so pretexto de hacerlo valer al máximo o debido a que el documento formal resulte desplazado por conceptos alternativos que, acerca de lo que es o debería ser una Constitución, admita o tolere el intérprete, situaciones todas de no muy difícil acaecimiento, pues tanto los contenidos del texto superior, como la función que este debe cumplir se ubican en fronteras fácilmente traspasables.

Sin pretensiones de exhaustividad, baste mencionar que la aceptación del carácter jurídico de la Constitución no la priva de su connotación política, ligada al hecho de situarse en los límites entre el Derecho y el poder al que busca organizar y contener, finalidad cuya búsqueda da lugar a interpretaciones de las cuales se suele destacar su carácter jurídico, pero también sus efectos políticos. Esto es parte de un 
delicado equilibrio que, sin embargo, se puede romper en el proceso interpretativo para acentuar los elementos políticos, en detrimento de la Constitución, disminuida en sus alcances o tergiversada, ya porque se le vacíe de contenido o porque se le fuerce a expresar algo que, en realidad, no tenga asiento en las posibilidades interpretativas jurídicamente válidas.

Otro flanco proclive a distorsiones es el de la complicada relación entre la Constitución y la realidad, asunto que, en medio de intensas discusiones, algunos dan por solucionado haciendo ver que los contenidos constitucionales incorporan sectores de la realidad y le asignan a cada uno de esos sectores sus respectivas consecuencias jurídicas. En cambio, otras posiciones insisten en la permanente disociación entre el texto superior y una realidad imposible de ser encauzada mediante regulaciones jurídicas y que debe ser preferida en la interpretación, a tal grado que el documento formal se convierte en simple hoja de papel contrarrestada por los factores reales de poder o por una subyacente constitución material, fundada en la historia y que, siendo la auténtica, prevalece y desplaza al texto adoptado por el poder constituyente.

Pero la Constitución también puede resultar difuminada a fuerza de hacer predominar concepciones de derecho natural solo accesibles a intérpretes capaces de desentrañar contenidos no perceptibles a partir de los textos y que siempre se imponen a ellos, o de proclamar la existencia de un orden objetivo de valores que actúa por debajo del documento constitucional para orientar todo el proceso interpretativo.

A todo lo anterior cabe agregar la desconfianza hacia el método literal, que ya no está en boga y podría ser obviado, o la disolución proveniente de la exagerada atención prestada al caso concreto, que orientaría la solución con mayor eficacia que las cláusulas abstractas, llamadas a ceder en aras de un conjunto de procedimientos multiplicados en un abultado número de test cada vez mejor perfilados para encorsetar en sus distintos pasos los datos del problema específico y producir la correcta mixtura de los contenidos previamente elegidos para la confrontación, aunque otros contenidos de la Constitución, que debería ser leída como una unidad, queden por fuera de la argumentación, pese a su relevancia y a causa de no hallar sitio en los estrictos moldes elaborados para hacer posible una ponderación que no admite el "balance" de todos los elementos que deberían ser tenidos en cuenta.

Nótese que cuando se incurre en alguno de los anotados riesgos se menoscaba o directamente se desconoce el carácter escrito de la Constitución y, por contera, su condición normativa, elementos estos que, conforme fue apuntado al inicio de este trabajo, son las condiciones que hacen posible la interpretación constitucional. Es claro que al eludir el texto y su contenido normativo no habrá nada diferente a una apariencia de interpretación que, aun cuando se ampare en el documento superior, no lo tiene realmente en cuenta o lo instrumentaliza, haciéndolo servir a otros propósitos escondidos bajo la fachada de una interpretación constitucional sin Constitución.

A fin de disipar las prevenciones ocasionadas por la circunstancia de que la interpretación constitucional tenga por objeto la Constitución, sería suficiente recordar que la elevada indeterminación de buena parte de sus cláusulas le facilita al intérprete operar en un extenso margen para concretar los valores, principios y fines prohijados por el mismo texto superior, adaptar la obra del poder constituyente a nuevas situaciones, retrasar las reformas y facilitar la permanencia de la 
Constitución, gracias a una interpretación evolutiva que no pierda el horizonte trazado por el documento formal.

Finalmente, resulta de interés apuntar que con frecuencia se recomienda como indispensable referente de la interpretación constitucional una apropiada teoría de la Constitución que, sin descuidar los componentes generales, sea una teoría del específico texto superior que en un momento dado rige para una determinada organización política estatal, pero la formulación de esa teoría supera con creces el objetivo de estas notas y, además, la precisión con que debería plantearse escapa al alcance de un trabajo dedicado a ciertos aspectos comunes a la interpretación que tiene por objeto a los documentos constitucionales genéricamente entendidos.

Recomendación bibliográfica

BOKENFORDE, E. W. (1993), Escritos sobre derechos fundamentales, Nomos Verlagsgesellschaft, Baden - Baden.

BELLO HUTT, D. E. (2017), "Contra la supremacía judicial en la interpretación de la constitución", Revus [Online], in print, online since 26 june. URL: htpp://revus.revues.org/3826; DOI: 10.4000/revus.3826.

DE OTTO Y PARDO, I. (2010), "La posición del Tribunal Constitucional a partir de la doctrina de la interpretación constitucional", Obras completas, Universidad de Oviedo, Centro de Estudios Políticos y Constitucionales, Oviedo, pp. 1159 1172.

FERRER MAC-GREGOR, E. (Coordinador), (2005), Interpretación constitucional (2 volúmenes), Editorial Porrúa, Universidad Nacional Autónoma de México, México.

GARCIA AMADO, J. A. (2003), Ensayos de Filosofía Jurídica, Editorial Temis, Bogotá.

GUASTINI, R. (2001), Estudios de teoría constitucional, Fontamara, México.

HESSE, K. (2011), Escritos de Derecho Constitucional, Fundación Coloquio Jurídico Europeo, Centro de Estudios Políticos y Constitucionales, Madrid.

JIMENEZ CAMPO, J. (1997), "Contra la Constitución material", Estudios de Derecho Público. Homenaje a Juan José Ruiz-Rico, Tecnos, Madrid.

MÜLLER, F. (1989), "Tesis acerca de la estructura de las normas jurídicas", Revista Española de Derecho Constitucional, núm. 27.

PRIETO SANCHIS, L. (1991), "Notas sobre la interpretación constitucional", Revista del Centro de Estudios Constitucionales, núm. 9.

SANCHEZ SANCHEZ, A. (2014), Sentencias interpretativas y control de constitucionalidad en Colombia, Ediciones Jurídicas Gustavo Ibáñez, Bogotá. 